\title{
Shrimp White Spot Syndrome - from Pathology to Pathogenomics
}

\author{
Kuan Fu Liu ${ }^{1,2}$, Wang-Jing Liu ${ }^{1}$, Guang-Hsiung Kou ${ }^{1}$ and Chu-Fang Lo ${ }^{1 *}$ \\ ${ }^{1}$ Institute of Zoology, National Taiwan University, Taipei 106, Taiwan, ROC \\ ${ }^{2}$ Tungkang Marine Laboratory, Taiwan Fisheries Research Institute, \\ Tungkang, Taiwan, ROC
}

\begin{abstract}
For shrimp with low-level white spot syndrome virus (WSSV, = PRDV) infection, environmental or physiological stresses can trigger replication of the virus and lead to a full-blown outbreak of white spot disease. This review will describe how pathogenomic studies have revealed some of the mechanisms that underlie this aspect of WSSV pathology. In the model that emerges, stressors activate shrimp STAT (signal transducer and activator of transcription), which is then annexed by the virus and used to activate the promoter of the immediate early gene WSSV ie1. This in turn leads to rapid replication of the virus.
\end{abstract}

Key words: white spot syndrome, penaeid acute viremia, pathogenomics, shrimp STAT, WSSV ie1 gene, WSSV, PRDV

White spot syndrome virus (WSSV), also known as penaeid rod-shaped DNA virus (PRDV), is the type species of the genus Whispovirus, family Nimaviridae (Vlak et al., 2005; Inouye et al., 1996). It is the causative agent of white spot disease, which has rapid onset and is usually lethal to the host. The virus is extremely virulent (Inouye et al., 1994; Momoyama et al., 1994; Nakano et al., 1994), has a wide host range (Lo et al., 1996; Flegel, 1997) and targets various tissues (Wongteerasupaya et al., 1995; Lo et al., 1997). Replication of the virus is easily triggered by physiological or environmental stress (OIE, 2006; Lo et al., 1997), but partly because no continuous shrimp cell line is currently available, the molecular mechanisms that control WSSV replication and gene transcription still remain unknown. Furthermore, WSSV is very unique, with over $90 \%$ of its ORFs showing no similarity to any known proteins (Tsai et al., 2004; 2006; Leu et al., 2009). The complete genome sequence of WSSV is available (WSSV-CN, accession no. AF332093; WSSV-TH, accession no. AF369029; WSSV-TW, accession no. AF440570), and there are now many published shrimp ESTs (O'Leary et al., 2006; Tassanakajon et al., 2006; Leu et al., 2007). However, in absence of functional evidence, the genetic sequence alone cannot fully unravel the molecular mechanisms by which WSSV causes disease. Consequently, in order to understand

\footnotetext{
* Corresponding author

E-mail: gracelow@ntu.edu.tw

This paper was presented in "5th International Symposium of the Japanese Society for Fish Pathology" held in Tokyo (October 18-19, 2008).
}

the physiological, metabolic, and pathological mechanisms used by WSSV, a global molecular understanding of the virus and its interactions with the host must be developed. This is the field of pathogenomics, which looks at how a pathogen's genetic sequence is related to the mechanisms by which the pathogen causes disease. In this review, we will present a case study showing how rapid replication of the virus is triggered by physiological or environmental stress. We will also show how WSSV genome sequencing was applied to the study of how WSSV causes disease.

We in fact followed two main lines of investigation. We began by screening for WSSV immediate early genes (IE genes), and this was followed by looking at how these IE genes interacted with host genes. This led to the finding that WSSV can use a shrimp protein, STAT (signal transducer and activator of transcription) to activate the WSSV ie1 promoter. Meanwhile, we also found that WSSV infection, environmental stress and physiological stress, can all activate STAT in shrimp. From all these observations, we inferred that the key to underlying mechanism is that WSSV is able to exploit antiviral STAT in shrimp. From this we were then able to put together our proposed model.

Viral IE genes are very important for viral infection. The expression of viral IE genes depends on the host cell machinery and occurs independently of any viral de novo protein synthesis. IE genes are especially important in determining host range. IE gene products may function as regulatory trans-acting factors and may serve to initiate viral replication events during infection (Friesen, 1997). 
To identify WSSV IE genes, protein synthesis had to be inhibited by treating the shrimp with the peptidyl transferase inhibitor cyclohexamide. Since the WSSV genome sequence was known, cDNA microarrays could be constructed, and these were used to screen for WSSV IE genes in the cycloheximide-treated shrimp (Liu et al., 2005). In this way, three WSSV IE genes were identified, with one of these genes, WSSV ie1, being of particular interest. Subsequent promoter assay revealed that WSSV ie1 has a very strong promoter, and that this ie1 promoter also functions in insect cells (sf-9 cells) (Liu et al., 2005). Like many other immediate early proteins, the WSSV IE1 protein has a transactivation domain; it can form dimers; and it also has DNA binding activity. All of these characteristics suggest that it can act as a transcriptional regulator (Liu et al., 2008). As one of the downstream genes that are regulated by ie1, we identified a transcription factor that positively regulates ie1 itself. Unexpectedly this turned out to be a shrimp STAT (PmSTAT; ie the Penaeus monodon STAT). This annexation of PmSTAT by WSSV was unexpected because STAT usually plays a role in host defense (Liu et al., 2007).

The Janus kinase (JAK)-STAT signaling pathway was first identified through studies on cytokines, and in the cytokine-mediated pathway, STATs execute the final step. STAT proteins are a family of transcription factors that are phosphorylated by activated JAK, then dimerize and subsequently translocate to the nucleus, where they transcriptionally activate appropriate genes to mediate various responses, including cell growth, cell differentiation and immune responses (Levy and Darnell, 2002; Shuai and Liu, 2003) . In vertebrates, STAT is part of the immune defense system, and it has been shown that STAT has a similar function in invertebrates too. In insect, the first evidence of the JAK/ STAT pathway being involved in immune responses was found in the mosquito Anopheles gambiae (AgSTAT). The AgSTAT translocated into the nucleus of the fat body cell upon bacterial infection (Barillas-Mury et al., 1999; Lin et al., 2004). Drosophila STAT was shown to play a defense role against bacterial infection, and also against viral infection (Agaisse and Perrimon, 2004; Dostert et al., 2005). In light of our previous result, the question then arises: how does WSSV interacts with STAT? We found the answer to this question while investigating WSSV ie1 promoter activity.

WSSV ie1 has been shown to have a very strong promoter (Liu et al., 2005). Using a dual luciferase assay system, we functionally mapped deletions of the WSSV ie1 promoter and found that a 23-mer fragment was critical for promoter activity. Sequence analysis of the WSSV ie1 promoter showed that this 23-mer fragment overlapped with a putative STAT binding motif, and the same dual luciferase assay was used with sitedirected mutagenesis to show that this STAT binding site really was critically important. The STAT binding site located within the $-84 /-64$ region of the WSSVie1 promoter, and electrophoretic mobility shift assays (EMSA) of this region with Sf9 cell nuclear extracts showed that the putative STAT binding motif was able to bind with insect STAT to form an (SFSTAT)-DNA complex. EMSA also showed that the same fragment binds with over-expressed PmSTAT in Sf9 cells, and that the recombinant PmSTAT transactivated the WSSV ie1 promoter in a dose-dependent manner. We further showed that knocking down STAT expression by dsRNA gene silencing reduced the expression level of WSSV ie1 mRNA (compared to the dsRNA anti-viral effect produced by the non-specific dsRNA control) and led to a reduction in virus copy number (unpublished data). All these data support the conclusion that WSSV successfully annexes a shrimp STAT to enhance the expression of the immediate early gene ie1 (Liu et al., 2007). But, as described below, WSSV and STAT also interact in another way as well.

It should be noted that STAT transcription is actually reduced after WSSV infection (Chen et al., 2008). However, the levels of activated STAT are increased. After WSSV infection, Western blot analysis using antiphosphorylated STAT antibody showed an increased level of phosphorylated (activated) STAT in shrimp cells (Liu et al., 2007; Chen et al., 2008), and this activated STAT was translocated from the cytoplasm to the nucleus (Chen et al., 2008). Under normal physiological conditions, microbial infection will activate the host immune-related signaling pathways and produce defense responses. But for WSSV, the outcome is quite different. Like other pathogens, WSSV causes STAT to be activated, and the activated STAT then dimerizes and translocates to the nucleus. However, once in the nucleus, instead of regulating the transcription of host immune genes, the STAT is annexed by WSSV and used to transactivate the promoter of the WSSV ie1.

A schematic of the proposed mechanism is shown in Fig. 1. Under stressful conditions, the STAT will be activated and this leads to transactivation of the WSSV ie1 gene and rapid replication of the virus. Recent results have shown that activation of STAT can be triggered not only by a pathogen, but also by environmental stressors (e.g. hypoxia) and physiological stressors (e.g. spawning) (unpublished data). Under these circumstances, if there is already a low-level WSSV infection, in the cell, then WSSV will exploit the activated STAT and use it to transactivate the WSSV ie1 gene. This is the mechanism by which stress triggers the rapid replication of the virus.

There are likely to be very many other cellular pathways that are impacted by WSSV infection (Leu et al., 2007; Wang et al., 2007; Wang et al., 2008). Science is very far from understanding the full range of mecha- 


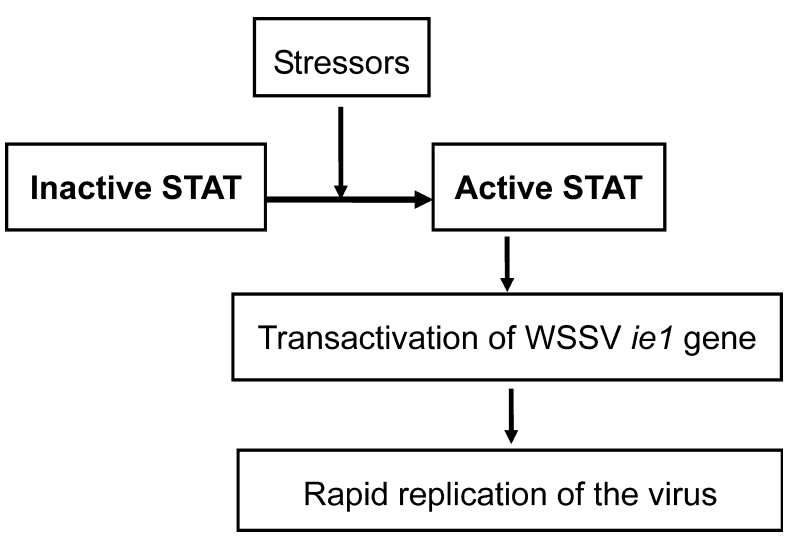

Fig. 1. Schematic of the mechanism by which stress leads to rapid replication of WSSV in infected cells.

nisms that are used by a pathogen to thwart its host, and equally far from understanding the mechanisms by which the host attempts to thwart the invader. The present review has described just one example of how pathogenomics can be used to study pathogen-host interaction. This is an area of science that is both important and of global interest.

\section{Acknowledgements}

This investigation was supported financially by Council of Agriculture grant (97AS-14.1.1-AQ-B1-4) and National Science Council grant (NSC96-2317-B-002005). We are indebted to Paul Barlow for his helpful criticism.

\section{References}

Agaisse, H. and N. Perrimon (2004): The roles of JAK/STAT signaling in Drosophila immune responses. Immunol. Rev., 198, 72-82.

Barillas-Mury, C., Y.-S. Han, D. Seeley and F. C. Kafatos (1999): Anopheles gambiae Ag-STAT, a new insect member of the STAT family, is activated in response to bacterial infection. EMBO J., 18, 959-967.

Chen, W. Y., K. C. Hoa, J. H. Leu, K. F. Liu, H. C. Wang, G. H. Kou and C. F. Lo (2008): WSSV infection activates STAT in shrimp. Dev. Comp. Immunol., 32, 1142-1150.

Dostert, C., E. Jouanguy, P. Irving, L. Troxler, D. GalianaArnoux, C. Hetru, J. A. Hoffmann and J. L. Imler (2005): The Jak-STAT signaling pathway is required but not sufficient for the antiviral response of drosophila. Nat. Immunol., 6, 946-953.

Flegel, T. W. (1997): Special topic review: major viral disease of the black tiger prawn (Penaeus monodon) in Thailand. World J. Microbiol. Biotech., 13, 433-442.

Friesen, P. D. (1997): Regulation of Baculovirus early gene expression. In: "The Baculoviruses" (ed. by L. K. Miller). Plenum Press, New York, pp. 141-170.

Inouye, K., K. Yamano, N. Ikeda, T. Kimura, H. Nakano, K. Momoyama, J. Kobayashi and S. Miyajima (1996): The penaeid rod-shaped DNA virus (PRDV), which causes penaeid acute viremia (PAV). Fish Pathol., 31, 39-45.

Inouye, K., S. Miwa, N. Oseko, H. Nakano and T. Kimura (1994): Mass mortalities of cultured kuruma shrimp,
Penaeus japonicus, in Japan in 1993: electron microscope evidence of the causative virus. Fish Pathol., 29, 149158. (in Japanese with English abstract)

Leu, J. H., C. C. Chang, J. L. Wu, C. W. Hsu, I. Hirono, T. Aoki, H. F. Juan, C. F. Lo, G. H. Kou and H. C. Huang (2007): Comparative analysis of differentially expressed genes in normal and white spot syndrome virus infected Penaeus monodon. BMC Genomics, 8, 120.

Leu, J. H., F. Yang, X. Zhang, X. Xu, G. H. Kou and C. F. Lo (2009): Whispovirus. In "Lesser Known Big DNA Viruses" (ed. by J. L. Van Etten). Springer-Verlag Berlin Heidelberg, pp. 197-227.

Levy, D. E. and J. E. Darnell Jr. (2002): Stats: transcriptional control and biological impact. Nat. Rev. Mol. Cell Biol., 3, 651-662.

Lin, C.-C., C.-M. Chou, Y.-L. Hsu, J.-C. Lien, Y.-M. Wang, S.-T. Chen, S.-C. Tsai, P.-W. Hsiao and C.-J. Huang (2004): Characterization of two mosquito STATs, AaSTAT and CtSTAT. J. Biol. Chem., 279, 3308-3317.

Liu, W.-J., Y.-S. Chang, C.-H. Wang, G.-H. Kou and C.-F. Lo (2005): Microarray and RT-PCR screening for white spot syndrome virus immediate-early genes in cycloheximidetreated shrimp. Virology, 334, 327-341.

Liu, W. J., Y. S. Chang, H. C. Wang, J. H Leu, G. H. Kou and C.F. Lo (2008): Transactivation, Dimerization, and DNAbinding Activity of White Spot Syndrome Virus immediate early protein IE1. J. Virol., 82, 11362-11373.

Liu, W. J., Y. S. Chang, A. H.-J. Wang, G. H. Kou and C. F. Lo (2007): WSSV has successfully annexed a shrimp STAT to enhance the expression of an immediate early gene (ie1). J. Virol., 81, 1461-1471.

Lo, C.-F., C.-H. Ho, C.-H. Chen, K.-F. Liu, Y.-L. Chiu, P.-Y. Yeh, S.-E. Peng, H.-C. Hsu, H.-C. Liu, C.-F. Chang, M.-S. Su, C.-H. Wang and G.-H. Kou (1997): Detection and tissue tropism of white spot syndrome baculovirus (WSBV) in captured brooders of Penaeus monodon with a special emphasis on reproductive organs. Dis. Aquat. Org., 30, 53-72.

Lo, C.-F., C.-H. Ho, S.-E. Peng, C.-H. Chen, H.-C. Hsu, Y.-L. Chiu, C.-F. Chang, K.-F. Liu, M.-S. Su, C.-H. Wang and G.H. Kou (1996): White spot syndrome baculovirus (WSBV) detected in cultured and captured shrimp, crabs and other arthropods. Dis. Aquat. Org., 27, 215-225.

Momoyama, K., M. Hiraoka, H. Nakano, H. Koube, K. Inouye and N. Oseka (1994): Mass mortalities of cultured kuruma shrimp, Penaeus japonicus, in Japan in 1993: histopathological study. Fish Pathol., 29, 141-148.

Nakano, H., H. Koube, S. Umezawa, K. Momoyama, M. Hiraoka, K. Inouye and N. Oseko (1994): Mass mortalities of cultured kuruma shrimp, Penaeus japonicus, in Japan in 1993: epizootiological survey and infection trails. Fish Pathol., 29, 135-139.

OIE (World Organisation for Animal Health; Office International des Epizooties) (2006): White spot disease. In "Manual of Diagnostic Tests for Aquatic Animals, 5th edition" (ed. by the OIE Aquatic Animal Health Standards Commission). OIE, Paris, pp. 379-391.

O'Leary N. A., H. F. III Trent, J. Robalino, M. E. T. Peck, D. J. Mckillen and P. S. Gross (2006): Analysis of multiple tissue-specific cDNA libraries from the Pacific whiteleg shrimp, Litopenaeus vannamei. Integr. Comp. Biol., 46, 931-939.

Shuai, K. and B. Liu (2003): Regulation of JAK-STAT signalling in the immune system. Nat. Rev. Immunol., 3, 900-911.

Tassanakajon A., S. Klinbunga, N. Paunglarp, V. Rimphanitchayakit, A. Udomkit, S. Jitrapakdee, K. Sritunyalucksana, A. Phongdara, S. Pongsomboon, P. Supungul, S. Tang, K. Kuphanumart, R. Pichyangkura and 
C. Lursinsap (2006): Penaeus monodon gene discovery project: The generation of an EST collection and establishment of a database. Gene, 384, 104-112.

Tsai, J.-M., H.-C. Wang, J.-H. Leu, H.-H. Hsiao, A. H.-J. Wang, G.-H. Kou and C.-F. Lo (2004): Genomic and proteomic analysis of thirty-nine structural proteins of shrimp white spot syndrome virus. J. Virol., 78, 11360-11370.

Tsai, J.-M., H.-C. Wang, J.-H. Leu, A. H.-J. Wang, Y. Zhuang, P. J. Walker, G.-H. Kou and C.-F. Lo (2006): Identification of the nucleocapsid, tegument, and envelope proteins of the shrimp white spot syndrome virus virion. J. Virol., 80, 3021-3029.

Valk, J. M., J. R. Bonami, T. W. Flegel, G. H. Kou, D. V. Lightner, C.-F. Lo, P. C. Loh and P. W. Walker (2005): Nimaviridae. In "VIIIth Report of the International Committee on Taxonomy of Viruses" (ed. by C. M. Fauquet, M. A. Mayo, J. Maniloff, U. Desselberger and L. A. Ball).
Elsevier Academic Press, London, pp. 187-192.

Wang, H. C., H. C Wang, J. H. Leu, G. H. Kou, A. H-J. Wang and C. F. Lo (2007): Protein expression profiling of the shrimp cellular response to white spot syndrome virus infection. Dev. Comp. Immunol., 31, 672-686.

Wang, H. C., H. C.Wang, T. P. Ko, Y. M. Lee, J. H. Leu, C. H. Ho, W. P. Huang, C. F. Lo and A. H-J. Wang (2008): WSSV ICP11 is a multi-functional DNA mimic protein that disrupts nucleosome assembly. Proc. Natl. Acad. Sci. USA., 105, 20758-20763.

Wongteerasupaya, C., J. E. Vickers, S. Sriurairatana, G. L. Nash, A. Akarajamorn, V. Boonsaeng, S. Panyim, A. Tassanakajon, B. Withyachumnarnkul, and T. W. Flegel (1995): A non-occluded, systemic baculovirus that occurs in cells of ectodermal and mesodermal origin and causes high mortality in the black tiger prawn Penaeus monodon. Dis. Aquat. Org., 21, 69-77. 